Prepared for the U.S. Department of Energy

under Contract DE-AC05-76RL01830

\title{
Status Report on the Creation of a Preliminary Data Model and Dictionary for a New Petrologic Database
}

RD Mackley

JA Serkowski

GV Last

September 2008

Pacific Northwest

NATIONAL LABORATORY

Proudly Operated by Battelle Since 1965 




\title{
DISCLAIMER
}

This report was prepared as an account of work sponsored by an agency of the United States Government. Neither the United States Government nor any agency thereof, nor Battelle Memorial Institute, nor any of their employees, makes any warranty, express or implied, or assumes any legal liability or responsibility for the accuracy, completeness, or usefulness of any information, apparatus, product, or process disclosed, or represents that its use would not infringe privately owned rights. Reference herein to any specific commercial product, process, or service by trade name, trademark, manufacturer, or otherwise does not necessarily constitute or imply its endorsement, recommendation, or favoring by the United States Government or any agency thereof, or Battelle Memorial Institute. The views and opinions of authors expressed herein do not necessarily state or reflect those of the United States Government or any agency thereof.

\author{
PACIFIC NORTHWEST NATIONAL LABORATORY \\ operated by \\ BATTELLE \\ for the \\ UNITED STATES DEPARTMENT OF ENERGY \\ under Contract DE-AC05-76RL01830
}

Printed in the United States of America
Available to DOE and DOE contractors from the Office of Scientific and Technical Information,
P.O. Box 62, Oak Ridge, TN 37831-0062;
ph: (865) 576-8401
fax: $(865)$ 576-5728
email: reports@adonis.osti.gov

\begin{abstract}
Available to the public from the National Technical Information Service, U.S. Department of Commerce, 5285 Port Royal Rd., Springfield, VA 22161 ph: (800) 553-6847 fax: $(703) 605-6900$ email: orders@ntis.fedworld.gov online ordering: http://www.ntis.gov/ordering.htm
\end{abstract}

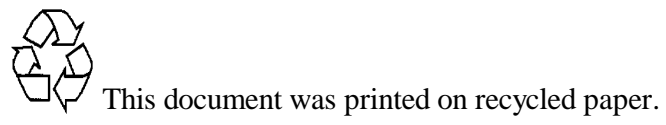




\title{
Revised Status Report on the Creation of a Preliminary Data Model and Dictionary for a New Petrologic Database
}

\author{
Rob D. Mackley \\ John Serkowski \\ George V. Last \\ 09/24/2008
}

\subsection{INTRODUCTION}

Petrologic, mineralogy, and bulk-rock geochemical data on geologic material of the Hanford Site have been collected for over 60 years. Typically, these data are organized in project-specific and partially-published sources (e.g. hard-copy reports). This information provides a foundation and technical baseline for understanding and defending conceptual models on the geologic framework, geochemical conditions and processes, reactive transport of contaminants, and subsurface remediation. Xie et al. (2003), using multivariate statistical analyses, found a distinction between Hanford and Ringold Formation sediments based on mineralogy and geochemistry. They recommended the continued collection, management, and use of these data for geologic characterization.

In fiscal year 2008 (FY08) Fluor Hanford, Inc. (FH) requested that the Pacific Northwest National Laboratory (PNNL) develop and update a prototype database for this information that would be suitable for transfer to a new Virtual Library module. This work is one of several inter-related activities being conducted under the Remediation Decision Support (RDS) function of the Soil and Groundwater Remediation Project to ensure maintenance of technical baseline data needed to resolve technical issues and support efforts to estimate contaminant migration and impacts.

This document describes the status of current efforts to include this geologic information into a relational database and presents the draft data structure of the prototype petrologic database. For the purposes of this document, this prototype database is called MinChem.

\subsection{STATUS AND APPROACH}

The original approach for this task was to create a set of data structures (tables and views) modeled after industry standards and structures currently present in HEIS (BHI 2002). These structures were envisioned to be implemented as a standalone database for transfer to a new Virtual Library module.

A preliminary/draft design of the data structures was presented to a petrologic database working group on June 16, 2008. Data users, generators, and technical experts in the field of database design and administration of Hanford Site data were in attendance. They provided important feedback that has helped to shape the current design. Chief among the comments and suggestions was to more closely model the petrologic database 
after HEIS, to the extent that once complete, the data in the petrology database could be loaded directly into existing HEIS structures with minimal modification. Recent and potential changes to the sample tables and other attributes in HEIS (such as those incorporated for the borehole geophysical log data), may now allow for more direct mapping of the petrologic data into the new HEIS data structures.

In its current form, MinChem includes some structures just as they appear currently in HEIS, as well as new structures that could be incorporated into HEIS at the time these databases were merged. This will allow us to 1) test the compatibility of HEIS with petrologic data, and 2) facilitate efficient migration of MinChem into the HEIS tables (this is currently planned for FY09).

\subsection{REQUIREMENTS}

Information for samples/analyses from boreholes and non-borehole sites (e.g. outcrops) will be included. The analytical methods include, but are not limited to, optical and electron microscopy, $\mathrm{x}$-ray diffraction, $\mathrm{x}$-ray fluorescence, and electron probe microanalysis. Results can be presented as quantitative, semi-quantitative, ranking, order of abundance, and presence/absence. The database structure must be designed in such a way as to allow a direct interface with other databases such as HEIS and the Hanford Borehole Geologic Information System (HBGIS).

The petrology database structure must accommodate certain data associated with the collection and analysis of geologic samples from the Hanford Site. Sample information must include project information, such as sampling purpose and point-of-contact, a threedimensional spatial location of the collection site, the stratigraphic horizon for the sample, if known, and the field details, such as name of person performing the sampling, sampling date, and methods used. The structure must be flexible enough to allow the inclusion of unlimited sample metadata that may vary from one study to the next.

For each sample, the structure will house one or more analytical results from a variety of mineralogical and petrological methods. Each result must be linked to a specific analytical laboratory, a laboratory preparation and analytical method, and a reference to where the data are published. A result may also have an uncertainty and quality level associated with it.

The final production database must be simultaneously accessible to Hanford Site researchers using existing network connections. In the present prototype status, the database does not have a user interface or connection to allow access from beyond the PNNL firewall for end users. These will be developed in the future as part of the steps toward making this a production database. 
PNNL-17663

\subsection{DESIGN AND IMPLEMENTATION}

\subsection{Strategy}

We looked at several strategies for tackling the storage of mineralogic, petrologic, and geochemical data. The most obvious solution is to incorporate it into an existing database. HEIS (BHI 2002), with data structures for storing sediment contaminant analysis, appears to be a suitable and appropriate repository. The data fits the basic HEIS model of sample, analysis method, and result. Even semi-quantitative data, such as abundance ranking, can be accommodated without undue creativity. However, our initial evaluation found that some data fields/attributes such as sub-sampling and sample preparation were not fully captured in the HEIS structure. However, recent changes to HEIS should remedy that situation. So, based on recent feedback from the working group, we developed a design centered around existing and proposed HEIS tables. Our intent is to test, populate, and exercise the preliminary data model outside of HEIS and then, after implementing any necessary modifications, migrate the data to HEIS.

Another strategy we had examined was to use an existing off-the-shelf or public domain system. While there are some references on the Internet to mineralogical and petrological databases and structures (e.g., http://www.earthchem.org/earthchemWeb/index.jsp), there do not appear to be any turnkey applications that meet the above-mentioned requirements. However, insights from the structures used by others have been incorporated into the design proposed in this document.

The design presented here addresses the requirements specified above and acknowledges the likelihood that MinChem might eventually be incorporated into HEIS. This latter condition, in many cases, dictates the table structures and key fields of the proposed design so that the transition to HEIS, if it occurs, will be straightforward.

We preserved HEIS field names whenever equivalences occurred, despite the fact that they do not always have consistent syntax. For example, the fields Method_Name, Lab_Code, and Con_ID in the HEIS RESULT table are all coded fields and, eventually, should all be consistently named with either a '_Code' or '_ID' suffix.

\subsection{Design Overview}

MinChem is a multi-user, relational database that resides on a networked, Windowsbased computer. The database management system is Microsoft Access 2003. Data are stored in 14 normalized tables. The tables are divided into two categories: 1) structural clones of HEIS database tables, and 2) tables exclusive to MinChem. The intent of this division is to make future migration to HEIS straightforward. Access to the data is currently available only through the native Access interface and a basic data retrieval form. Additional interfaces will be developed with guidance from users. 


\subsection{Table Structure}

Figure 1 shows the MinChem table structure. Tables with names including the prefix 'mc' (e.g., mcAttribute) indicate they are specific to MinChem; those with a prefix of 'heis' (e.g., heisResult) are structural clones of existing HEIS tables. The structure centers about the heisSample and heisResult tables, which house the sample information and analytical result data, respectively. The other tables provide additional information on and validation for fields in these two tables where codes are used for brevity. The heisValid_Codes table provides additional field value lookups.

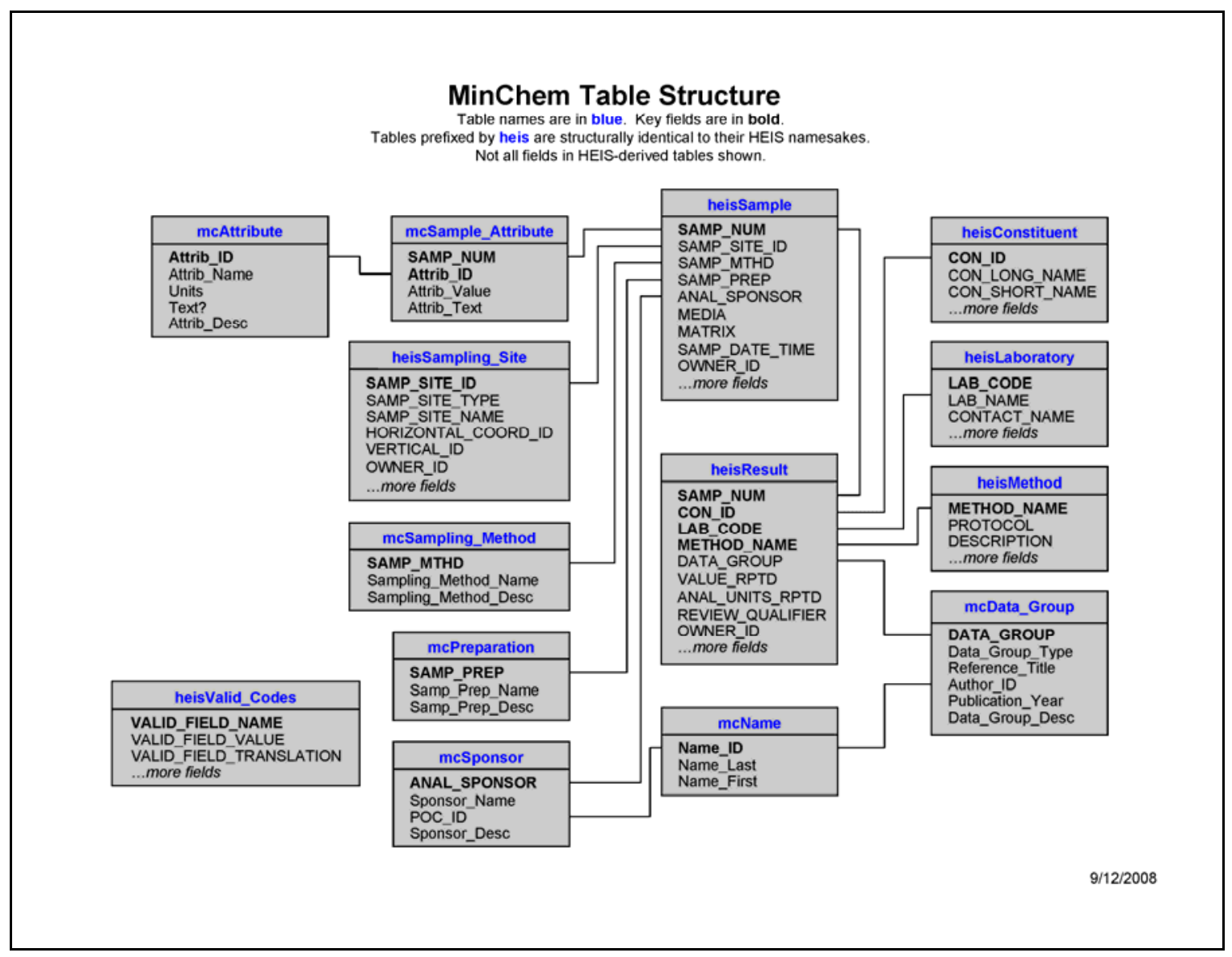

Figure 1. MinChem table structure.

The mcSample_Attribute table provides a mechanism to attach an indefinite number of attributes to any sample. An attribute can be any numeric or textual value associated with the sample, other than an analysis result. We provide this capability in anticipation of the inevitable bits of descriptive information that certain projects will find useful but are impossible to predict ahead of time. For example, a researcher may wish to record something that is not normally relevant to most projects (e.g., the wind speed at the time of sample collection) and then later have the ability to query their data on this information. 
The table heisSampling_Site is based on a prototype for a revised version of the existing HEIS SAMPLING_SITE table. Currently, samples in HEIS are associated with either a WELL_NAME or, if not collected from a well, a SAMP_SITE_ID. In this proposed HEIS structure, which has not been formally documented yet, every sample will have a SAMP_SITE_ID associated with it. Moreover, sampling sites may have hierarchical associations with other sampling sites. For example, a sample may be extracted from the deepest few centimeters of a well core sample collected during drilling. The severalcentimeter-long sampling site is assigned a unique code and described in terms of its location with respect to the drill core. The entire core sample, which may be a meter long, may be assigned to another sampling site that defines the depth range from which the core was obtained in the well. The core is associated with the sampling site for the entire well, and the well, in turn, may be associated with a sampling site defining the area of a waste facility. Thus, the small rock sample may be associated to the drill core, the well from which the drill core was extracted, and the waste facility at which the well is located. This permits very powerful location-based queries for samples.

\subsection{Data Dictionary}

Table 1 is an explanation of the fields in the data dictionary tables. Tables 2 through 7 are the data dictionary for each new MinChem table (those with table names prefixed with ' $m c$ '). Key fields, those that uniquely define a record, are shown in bold. The complete data dictionary for the HEIS tables may be found in BHI 2002.

Table 1. Key to data dictionary .

\begin{tabular}{|l|l|}
\hline \multicolumn{1}{|c|}{ Column } & \multicolumn{1}{c|}{ Description } \\
\hline Contents & Brief description of what is in the table \\
Field & Name of table field \\
Type & Data type of field: T = text, $\mathrm{N}=$ numeric, I = index (long integer), B = boolean \\
Description & Description of field - contents and limitations \\
Example & Examples of data in this field \\
Lookup & Name of VALID_FIELD_NAME or lookup table if coded field \\
\hline
\end{tabular}

\section{Table 2. Table mcAttribute}

Contents: Each record is a unique attribute type that may be associated with a sample. Attributes are sample descriptors for which there is no structure in table heisSample. In particular, attributes are parameters that a user might wish to use as selection criteria in a query. An attribute can have either a text value or a numeric value, but not both.

\begin{tabular}{|l|c|l|l|l|}
\hline \multicolumn{1}{|c|}{ Field } & Type & \multicolumn{1}{|c|}{ Description } & \multicolumn{1}{c|}{ Example } & \multicolumn{1}{c|}{ Lookup } \\
\hline Attrib_ID & I & Code for sample attribute name & 1,2 & \\
Attrib_Name & T & Unique identifier for the sample attribute & "Size Fraction” & \\
Units & T & Units of attribute & "Rank", “\%Vol" & MC_UNITS \\
Text? & B & True if attribute is text; false if number & True, False & \\
Attrib_Desc & T & Description of attribute & "sample block" & \\
\hline
\end{tabular}


Table 3. Table mcData_Group

\begin{tabular}{|c|c|c|c|c|}
\hline Field & Type & Description & Example & Lookup \\
\hline DATA_GROUP & $\mathrm{T}$ & $\begin{array}{l}\text { Code of form: MCREFnnnnnnn, } \\
\text { where nnnnnnn is a unique number. }\end{array}$ & "MCREF0000001" & \\
\hline Data_Group_Type & $\mathrm{T}$ & $\begin{array}{l}\text { The type of media on which source } \\
\text { data reside }\end{array}$ & "Document" & DATA_GROUP_TYPE \\
\hline Reference_Title & $\mathrm{T}$ & Title of document of name of file & "The Rock Report" & \\
\hline Author_ID & I & $\begin{array}{l}\text { Code for name of primary author or } \\
\text { file owner }\end{array}$ & 1,2 & \\
\hline Publication_Year & $\mathrm{N}$ & $\begin{array}{l}\text { Year in which document was public } \\
\text { or file created }\end{array}$ & 1998 & \\
\hline Data_Group_Desc & $\mathrm{T}$ & Description of reference & "PNNL-17663" & \\
\hline
\end{tabular}

Table 4. Table mcName

Contents: This table contains the first and last names of people referred to in the database.

\begin{tabular}{|l|c|l|l|c|}
\hline \multicolumn{1}{|c|}{ Field } & Type & \multicolumn{1}{|c|}{ Description } & \multicolumn{1}{c|}{ Example } & Lookup \\
\hline Name_ID & I & Unique ID for name & 1,2 & \\
Name_Last & T & Person's last name & "Serkowski" & \\
Name_First & T & Person's first name or initial & "John", "AJ" & \\
\hline
\end{tabular}

\section{Table 5. Table mcPreparation}

Contents: Sample preparation is the modification of a sample between the time it is collected and the time it is analyzed. There may be some overlap with sample collection and sample analysis, as both these activities may also modify the sample to some degree, so preparation is reserved for those actions not addressed in the sampling method or analysis method. Typically, procedures such as sieving, sorting, drying, crushing, etc., are considered sample preparation.

\begin{tabular}{|l|c|l|l|l|}
\hline \multicolumn{1}{|c|}{ Field } & Type & \multicolumn{1}{c|}{ Description } & Example & Lookup \\
\hline SAMP_PREP & T & Unique short name for sample preparation & "Sieve2" & \\
Samp_Prep_Name & T & Long name for sample preparation & "Sieve 2 Mesh" & \\
Samp_Prep_Desc & T & Description of sample preparation & "sieved ..." & \\
\hline
\end{tabular}

Table 6. Table mcSample_Attribute

Contents: This table contains attribute data for a sample. An attribute record can have either a text value or a numeric value, but not both.

\begin{tabular}{|c|c|c|c|c|}
\hline Field & Type & Description & Example & $\overline{\text { Lookup }}$ \\
\hline SAMP_NUM & $\mathrm{T}$ & $\begin{array}{l}\text { Sample number associated with } \\
\text { attribute }\end{array}$ & "MC0000001" & heisSample \\
\hline Attrib_ID & I & Code for sample attribute name & 1,2 & mcAttribute \\
\hline Attrib_Value & $\mathrm{N}$ & $\begin{array}{l}\text { Numeric value if attribute type is } \\
\text { Text? = False }\end{array}$ & 3.14 & \\
\hline Attrib_Text & $\mathrm{T}$ & $\begin{array}{l}\text { Text string if attribute type is Text? = } \\
\text { True }\end{array}$ & "sG" & \\
\hline
\end{tabular}


Table 7. Table mcSponsor

\begin{tabular}{|c|c|c|c|c|}
\hline Field & Type & Description & Example & $\overline{\text { Lookup }}$ \\
\hline ANAL_SPONSOR & $\mathrm{T}$ & $\begin{array}{l}\text { Code of form: MCnnnn, where nnnn } \\
\text { is a unique number. }\end{array}$ & "MC0001" & \\
\hline Sponsor_Name & $\mathrm{T}$ & Descriptive name of sponsor & "BWIP" & \\
\hline POC_ID & I & ID for sponsor point of contact & 1,2 & mcName \\
\hline Sponsor_Desc & $\mathrm{T}$ & Description of sponsoring project & "Basalt Waste ..." & \\
\hline
\end{tabular}

\subsection{Interfaces}

A formal user interface is not specified for MinChem at this time. Data retrieval, processing, and output is handled using the native Access interface, which includes a complete set of query, report, and programming tools.

Likewise, there are no specialized data entry programs. Data may be loaded by direct manual input into tables, cut-and-paste operations, and native Access data import processes.

\subsection{Implementation}

MinChem table structures and relationships are stored in the Microsoft Access 2003 relational database management system. This software was chosen because it is relatively easy to use, has multi-user capability, interfaces with HEIS, and is widely available to Hanford Site contractors.

The data tables reside in a single Access MDB file on a networked, Windows-based server computer. For those within the PNNL firewall, access to the database is made by linking to the networked tables through a local Access database. In addition to the table links, each user's local Access database may include queries, forms, reports, and programs for retrieving, processing, and outputting the data. These local tools may be developed by the user, or provided by the MinChem development team.

Once the prototype database has been tested and the need for the production database arises, easy access to the database for all Hanford end users will be implemented (likely by incorporating the MinChem data and structures into HEIS. 


\subsection{SECURITY AND CONFIGURATION CONTROL}

As a prototype, MinChem has more lenient configuration control than a full production database.

Programs and interfaces written by MinChem developers will be tested and all tests documented. Changes to existing programs will require retesting of relevant parts. All programs will be internally documented and numbered (using the standard major.minor scheme) to distinguish versions.

Data loading will only be done by MinChem development team members. All other users will only have read access to the database. All analysis result data will be loaded with a "U" (unvalidated) REVIEW_QUALIFIER until a validation procedure is established and the data reviewed.

Database backup will be done daily using PNNL's Connected DataProtector service.

\subsection{USER GUIDE}

As user interaction with MinChem data is currently limited to the native Access interface, this user guide focuses on connection to the database and a brief overview of some useful Access commands.

\subsection{Obtaining Access to MinChem}

Staff wishing to use MinChem must contact the MinChem technical administrator, Rob Mackley, at 371-7178. They will receive a static (most-recent snapshot of the database) copy of the MS Access (.mdb file).

\subsubsection{Viewing and Querying Data}

To view data in a table, double click its name in the Table Objects window. You may scroll through the table using scroll bars at the right or sort the records on a field by clicking on a field name and pressing the $\stackrel{\mathrm{A}}{\mathrm{Z}} \downarrow$ or $\stackrel{\mathrm{Z}}{\mathrm{A}} \downarrow$ button. An easy query can be

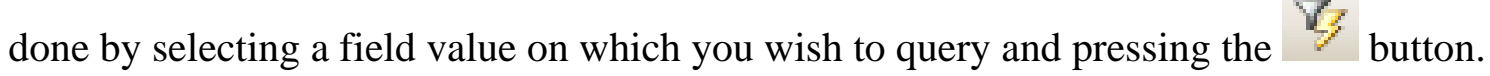
This retrieves all records containing the selected field value. To show all the records again, press the $\square$ button.

More advanced queries can be made by creating a Queries Object. See Access help for details. 


\subsection{SUMMARY}

A preliminary database has been developed that will allow mineralogy and bulk-rock geochemical information to be managed under configuration control and facilitate electronic querying. The database is currently developed in Microsoft Access. Each field and table has been described in a data dictionary. The current state of the prototype database reflects the original intent to deliver a standalone petrology database for transfer to a new Virtual Library module. Recent and upcoming developmental changes taking place in HEIS data structures might make it more feasible than previously recognized to include the petrology database directly into HEIS rather than create a separate Virtual Library module.

\subsection{FUTURE PLANS}

Efforts planned for FY09 include:

1) Create a plan and timeline for the migration of MinChem to HEIS.

2) Develop a data validation procedure to assure the quality of data entered into MinChem.

3) Continue entering data from the Excel data file of Xie et al. (2003) into MinChem, as well as legacy and newer data. These data will come from both electronic and non-electronic (hardcopy) sources.

4) Design a graphical user interface (GUI) that will serve as a front-end portal to querying and downloading data. Such an interface would use existing HEIS GUIs wherever practical.

\subsection{REFERENCES}

BHI, 2002, Hanford Environmental Information System - Detailed Design Specification. BHI-01639 Rev. 0, Bechtel Hanford Inc., Richland, WA.

Xie YL, CJ Murray, GV Last, and RD Mackley. 2003. Mineralogical and Bulk-Rock Geochemical Signatures of Ringold and Hanford Formation Sediments. PNNL14202, Pacific Northwest National Laboratory, Richland, WA. 